\author{
Military Technical College \\ Kobry El-Kobbah, \\ Cairo, Egypt.
}

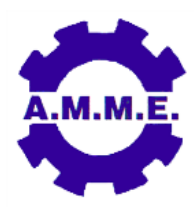

$17^{\text {th }}$ International Conference on Applied Mechanics and Mechanical Engineering.

\title{
THE EFFECT OF CUTTING PARAMETERS AND THE FREQUENCY OF INTERRUPT ON CERAMIC TOOL WEAR IN HARD TURNING
}

\author{
O. M. Abdal-Aaziz' ${ }^{1}$ E. A. Bary², A. Mahrous ${ }^{3}$ and A. Barakat ${ }^{4}$
}

\begin{abstract}
Some of the advantages of using turning instead of grinding for the finish machining of hardened steel surfaces are: high flexibility, the ability to cut complex surfaces with a single machine set up, cost of the process, and the possibility of turning without cutting fluid. On the other hand, turning is not very suitable for cutting hardened interrupted surfaces, since most of the tools used in this operation are not very tough. When interrupted surfaces are turned, the tools are required to be sufficiently tough to resist impact against workpiece interruptions .Ceramic tools were used in the radial turning of hardened steel with one type of surface interruption.

The goal was to study the effects of frequency of interruption of $42 \mathrm{CrMo} 4$ hardened steel workpiece with four types of surfaces interruption and machining parameters (cutting speed, feed, and depth of cut) on cutting forces, metal removal and tool wear behavior. The results show significantly that as the number of interruptions, cutting speed, feed and depth of cut increase, the flank wear increases and cutting length decreases.
\end{abstract}

\section{KEY WORDS}

Interrupted hard turning, ceramic tool, tool wear

1 Dept. of Industrial Systems Engineering, October University for Modern Science and Arts (MSA), 6th of October, Giza, Egypt.

2 Dept. of Industrial Systems Engineering, October University for Modern Science and Arts (MSA), 6th of October, Giza, Egypt.

3 Dept. of Mechanical Engineering, Helwan University, Cairo, Egypt.

4 Dept. of Mechanical Engineering, Helwan University, Cairo, Egypt. 


\title{
NOMENCLATURE
}

\author{
a depth of cut $(\mathrm{mm})$ \\ f cutting feed ( $\mathrm{mm} / \mathrm{rev}$.) \\ Fc main cutting force (tangential force) $(\mathrm{N})$ \\ Fp passive force (radial force) $(\mathrm{N})$ \\ $\mathrm{Ff}$ feed force (axial force) (N) \\ $\checkmark$ surface cutting speed ( $\mathrm{m} / \mathrm{min}$.)
}

\section{INTRODUCTION}

Parts with hardness exceeding 45 HRC can be machined by hard turning, which provides surface roughness, dimensional and shape tolerances similar to those achieved in grinding. The advantages of hard turning include high flexibility (it is possible to carry out internal, external and face turning in just one fixation of the workpiece, which is rarely possible in grinding), and low cost of operation ( turning lathes are usually cheaper than grinding machines, but the cost of the tool per machined part is usually higher in turning). However, with the development of new tool materials and strategies to turn hardened steel aiming to increase tool life, the cost of the tool per machined part tends to decrease) [1], the ability to cut complex geometries with a single machine setup are the main technological advantages of hard turning over the grinding process [2] and even the possibility of dry machining (fluid in grinding is a big problem, because the wet small chips becomes a kind of mud, difficult to be handled and recycled) [3].

Ceramics and CBN are very rigid machining tools, which can ensure the same accurate geometrical and dimensional tolerances. Within the last years, hard turning operations have become more and more capable with respect to surface roughness and IT standards [3].

In industrial applications, many components that are quenched and tempered before the finish turning operation have surfaces interrupted by holes, lubrication channels, splines and key slots (Juvinall and Marshek,) [4]. Interrupted turning of hardened surfaces imposes extra difficulties on machining operations. In such cases, a PCBN rather than a ceramic tool is preferable, due to its high hardness allied to moderate toughness. However, there are some restrictions on its use in the machining of hardened steels with interrupted surfaces, because tools generally used for this purpose are brittle and have little resistance against the typical shocks of interrupted cutting. On the other hand, interrupted surfaces are typical for turned parts, lending importance to the study of the turning of such surfaces in hardened steel parts [3].

The main goal of this work is to contribute to the studies about this problem. Turning experiments were carried out on different workpiece surfaces and using ceramic tool. The final purpose was to study the effect of the frequency of interruption and cutting conditions on tool wear, cutting force and tool life. 


\section{TOOLS MATERIALS AND GEOMETRIES FOR HARDENED STEEL TURNING}

Wear resistance and chemical stability are the most important properties of a tool material intended for hardened steel turning. The hardened workpiece surface has an abrasive effect on the tool material, and the high temperature on the cutting edge causes diffusion between tool and chip. Moreover, if the surface has any kind of interruption, toughness is an additional necessary property of the tool material, in order to prolong tool life (Wellein and Fabry) [5].

Ceramics and CBNs are the best tool materials for this type of operation, due to their high hot hardness and wear resistance. Their hardness and chemical stability enable them to withstand the high thermal and mechanical loads of such machining operations. CBN has a higher hardness than ceramic tools at both low and high temperatures. Other CBN properties such as high thermal conductivity and low thermal expansion coefficient are also important when using such tools in hardened steel turning. Ceramic has other good properties for use in hardened steel turning, such as hot hardness, wear resistance, and excellent chemical stability. Ceramic has chemical stability higher than CBN.

Several studies about ceramic and CBN use in hard turning with continuous cutting have been done (Chou and Evans, Matsumoto and Diniz) [6]. However, the study of hard turning on interrupted surfaces is limited to a few publications.

\section{EXPERIMENTAL PROCEDURES}

The work material used in the research was $42 \mathrm{CrMo} 4$ hardened steel. It was received as $30 \mathrm{~mm}$ diameter partially cut into separate $145 \mathrm{~mm}$ segments. An undercut of $5 \mathrm{~mm}$ width was made after $20 \mathrm{~mm}$ so that the $145 \mathrm{~mm}$ segment had six partitions. The workpiece surface had four types of surfaces: 1, 2, 3 and 4 grooves each groove was made with $3 \mathrm{~mm}$ width and $2 \mathrm{~mm}$ length, as shown in Fig.1. All solid bars were used in the experiment are hardened to achieve a hardness of approximately 52 HRC. Table 1 shows the chemical properties of the work materials. After hardening, the work pieces were again skin turned by ceramics tool to have uniform surface roughness.

A PLG 52 Super Precision CNC Lathe was used for all experiments. This was suitable for changing the speed and feed during the turning operation, as shown in Fig.2. The tool flank wear was measured by CCD camera [Sony DSC W1 digital], equipped with changeable standard lenses and adapter, fixture, and computer software, as shown in Fig.3.

For tool wear investigations, a special open source computer program was written using MATLAB [7]. The software has the ability to give all relevant details about the area of wear such as the maximum wear, the average wear, as shown in Fig.4.

The cutting forces were measured by DKM2010 turning dynamometer, It records all cutting forces during experimental turning operations using a PC-based data acquisition system. It measures forces on the cutting tool up to $2000 \mathrm{~N}$ with a resolution of $1 \mathrm{~N}$; these are: 
$\mathrm{F}_{\mathrm{c}}$ main cutting force (tangential force) and it acts in the direction of the cutting speed.

$\mathrm{F}_{f}$ feed force (axial force) right and left direction, it acts on the tool in the direction parallel with the direction of feed.

$F_{p}$ the passive force (radial force) and passive force drawing into work piece, shown in Fig.5.

Ceramic cutting inserts were used to clean the surface of the heat treated workpiece, and were used to carry out all test cuts. The ceramic inserts used for test cuts had a geometry specified by ISO CNGA 120408 T02520, as shown in Fig.6

\section{Tool Wear}

Before beginning any experiment, turning passes are performed on all workpieces to remove the scale from heat treatment. These cleaning passes also help to remove initial out of roundness that was present in the bar after heat treatment. The testing procedure consisted of turning ten passes of $20 \mathrm{~mm}$ in length in each partition of workpiece. The flank wear was recorded after $200 \mathrm{~mm}$ of turning length, the experiment was stopped when the average flank wear reached $0.2 \mathrm{~mm}$ or the tool was broken. The three components of cutting forces were recorded during the life of each tool at regular intervals.

\section{RESULTS AND DISCUSSION}

\section{Effect of Surface Cutting Speed}

In the experiments of surface cutting speed, three experiments were carried out at $56.5 \mathrm{~m} / \mathrm{min}, 75.4 \mathrm{~m} / \mathrm{min}$ and $94.2 \mathrm{~m} / \mathrm{min}$. Surface cutting speed and depth of cut 0.3 $\mathrm{mm}$ and cutting feed $0.06 \mathrm{~mm} / \mathrm{rev}$. Fig. 7 shows the effect of cutting speed on flank wear, Fig.8 shows the effect of surface cutting speed on metal removal and Fig.9 shows the tool flank wear and failure after the end of the experiment.

From the figures, the graphs have typical wear behavior, as the surface cutting speed was increased the flank wear increased, the metal removal decreased due to the rupture of the insert. Also as the surface cutting speed was increased, tool failure occurred earlier.

\section{Effect of Depth of Cut}

In the experiments of depth of cut, three experiments were carried out at $0.1 \mathrm{~mm}, 0.3$ $\mathrm{mm}, 0.5 \mathrm{~mm}$ depth of cut and $94.2 \mathrm{~m} / \mathrm{min}$ surface cutting speed and cutting feed 0.06 $\mathrm{mm} / \mathrm{rev}$. Fig.10 shows the effect of depth of cut on flank wear, Fig.11 shows the effect of depth of cut on metal removal and Fig.12 shows the effect of depth of cut on cutting length. 
From the shown figures; as the depth of cut was increased the flank wear increased and the cutting length decreased due to the rupture of the insert. But the metal removal increased with the increase of the depth of cut before reaching $0.2 \mathrm{~mm}$ average flank wear.

\section{Effect of Cutting Feed}

In the experiments of cutting feed, three experiments were carried out, at $0.034,0.06$, $0.1 \mathrm{~mm} / \mathrm{rev}$. cutting feed and $94.2 \mathrm{~m} / \mathrm{min}$. surface cutting speed and $0.3 \mathrm{~mm}$ depth of cut. Fig. 13 shows the effect of cutting feed on flank wear, Fig.14 shows the effect of cutting feed on uncut chip length and Fig.15 shows the effect of cutting feed on cutting length and flank wear.

From the shown figures, as the cutting feed was increased the flank wear decreased and the cutting length increased. Up to a certain value the flank wear increased, the cutting length decreased with the increase of the cutting feed, and the tool failed. This value is $0.1 \mathrm{~mm} / \mathrm{rev}$. for the tool nose radius $0.8 \mathrm{~mm}$. As the cutting feed was increased the uncut chip length decreased, while the cutting length increased up to a certain value after which the cutting length decreased because the cutting force increased.

\section{Effect of Frequency of Interruption}

Four experiments were carried out, at $0.06 \mathrm{~mm} / \mathrm{rev}$. cutting feed, and $75.4 \mathrm{~m} / \mathrm{min}$. surface cutting speed and $0.3 \mathrm{~mm}$ depth of cut. Fig. 16 shows the effect of frequencies of interruption on average flank wear, Fig.17 shows the effect of frequencies of interruption on cutting length, Fig.18 shows the effect of frequencies of interruption on metal removal.

From the shown figures, with increasing frequency of interruption, the flank wear increases and the cutting length decreases and tool life decreases. As the frequencies of interruption were increased the metal removal decreased because the cutting force increased.

\section{CONCLUSIONS}

Based on the above results for the interrupted turning of hardened $42 \mathrm{CrMo} 4$ steels with $52 \mathrm{HRC}$, using Ceramic tools and in conditions similar to those used in this work, it can be concluded that:

- Tool life is sensitive to the frequency of interruption, as the frequency of interruption increases by about 50\%,the flank wear increases, the cutting length decreases by about $33 \%$ and also the metal removal because of the cutting force increases.

- The passive component is typically the largest one, followed by the cutting component, and finally the feed component. 
- As the tool wear increases the passive and cutting components increase. When the tool fails the passive component is extremely increased, thus the passive component is used to detect tool failure.

- As the surface cutting speed increases by about $25 \%$, the flank wear increases and metal removal decreases by about $9.5 \%$.

- As the depth of cut increases by about $66.7 \%$, the flank wear increases and the cutting length decreases by about $38 \%$, and the passive component and cutting component increase, but the metal removal is increased by about $3.5 \%$.

- As the cutting feed increases by about $76 \%$, the flank wear decreases and the longitudinal cutting length increases by about $50 \%$ while the uncut chip length decreases by about $23 \%$. Up to a certain value the flank wear increases and the tool fails, the longitudinal cutting length decreases as the cutting feed is increased.

\section{REFERENCES}

[1] Vitor A. Godoy, Anselmo E. Diniz (Turning of interrupted and continuous hardened steel surfaces using ceramic and CBN cutting tools) Journal of Materials Processing Technology 211 (2011) 1014-1025

[2] Adilson J. Oliveira, Anselmo E. Diniz, Davi J.Ursolino(Hard turning in continuous and interrupted cut with PCBN and whisker-reinforced cutting tools) Journal of Materials Processing Technology 209 (2009) 5262-5270

[3] Anselmo E. Diniz, Adilson J. Oliveira (Hard turning of interrupted surfaces using CBN tools) journal of materials processing technology 195 ( 2008 ) 275-281

[4] Juvinall, R.C., Marshek, K.M., 1999. (Fundamentals of Machine Component Design), third ed. John Wiley \& Sons, Hoboken.

[5] Wellein, G., Fabry, J., 1998. (Hard Turning is More Than the Application on CBN). Cutting Technology, Kennametal Hertel.

[6] Chou, Y.K., Evans, C.J., 1999. (Cubic boron nitride tool wear in interrupted hard cutting). Wear 225-299, 234-245.

[7] A. mahrous, A. mousa and A. barakat "Applying Artificial Neural Network in hard turning processes"Helwan University, Helwan (2008). 

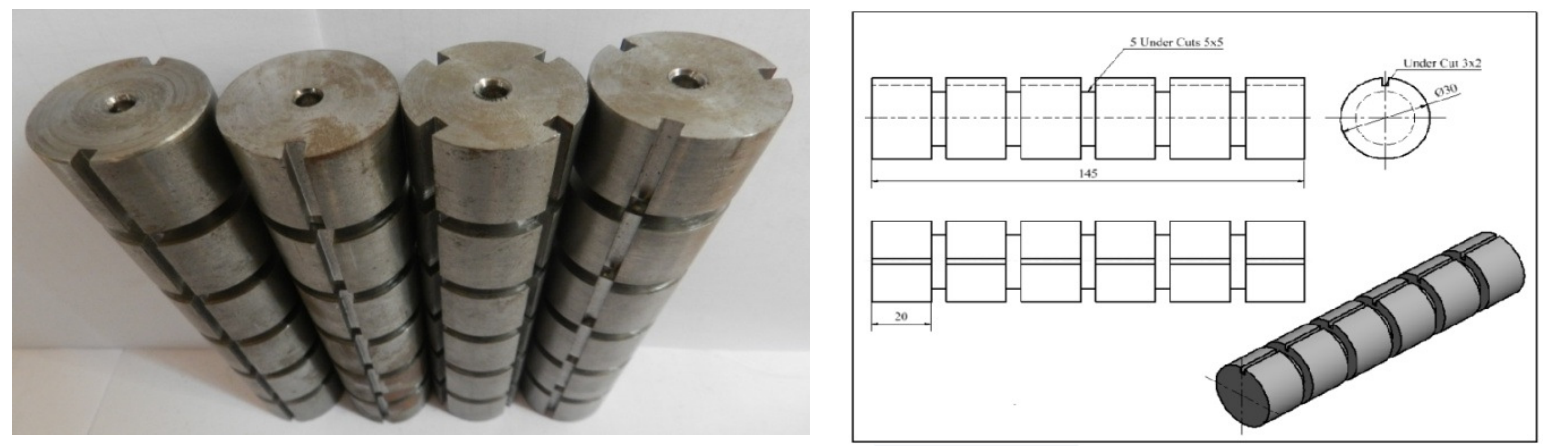

Fig.1. Workpieces used in the experiment.

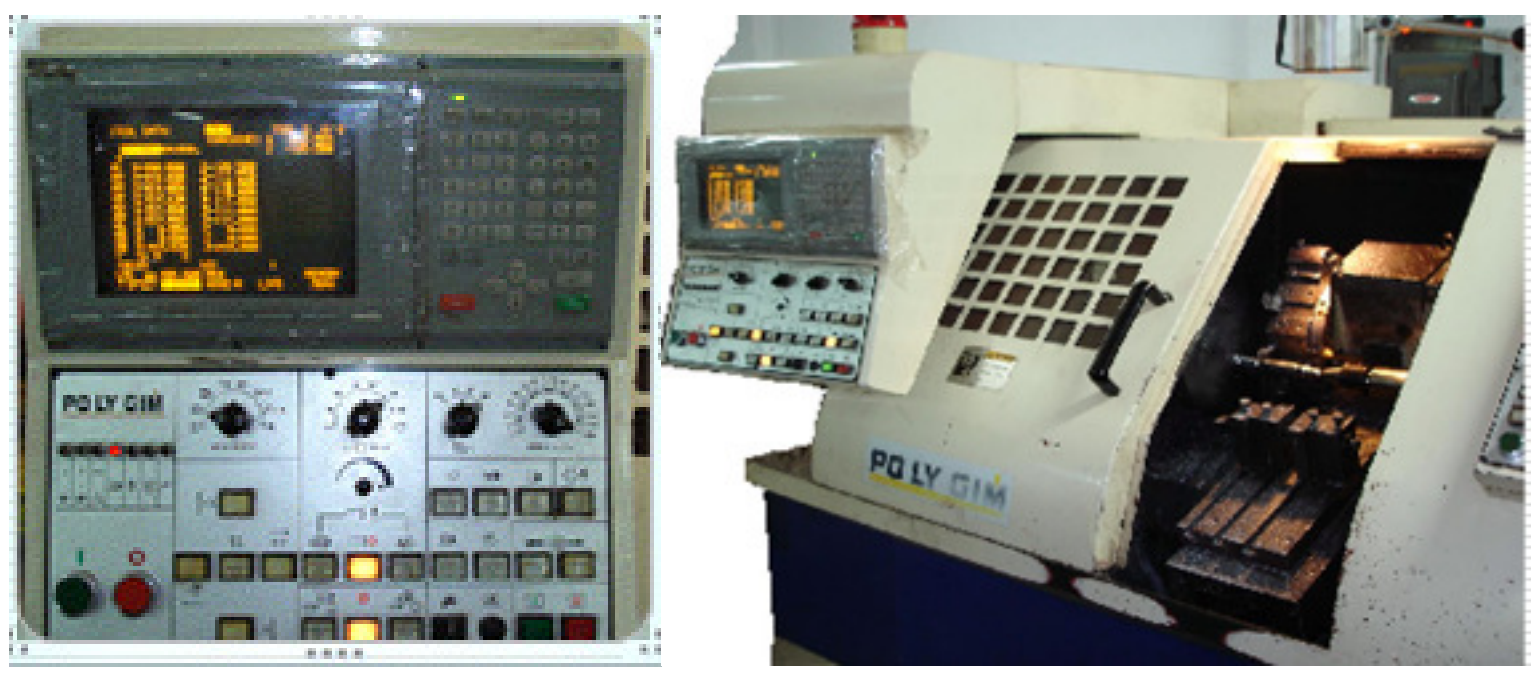

Fig.2. Super precision CNC lathe.

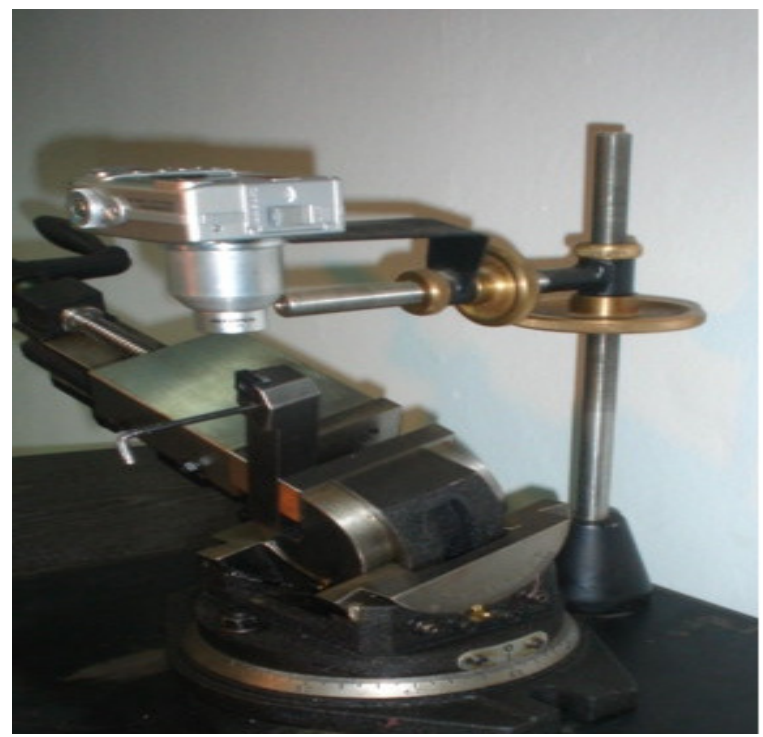

Fig.3. CCD camera equipped with changeable standard lenses and adapter, 2D stand and 3way vice. 


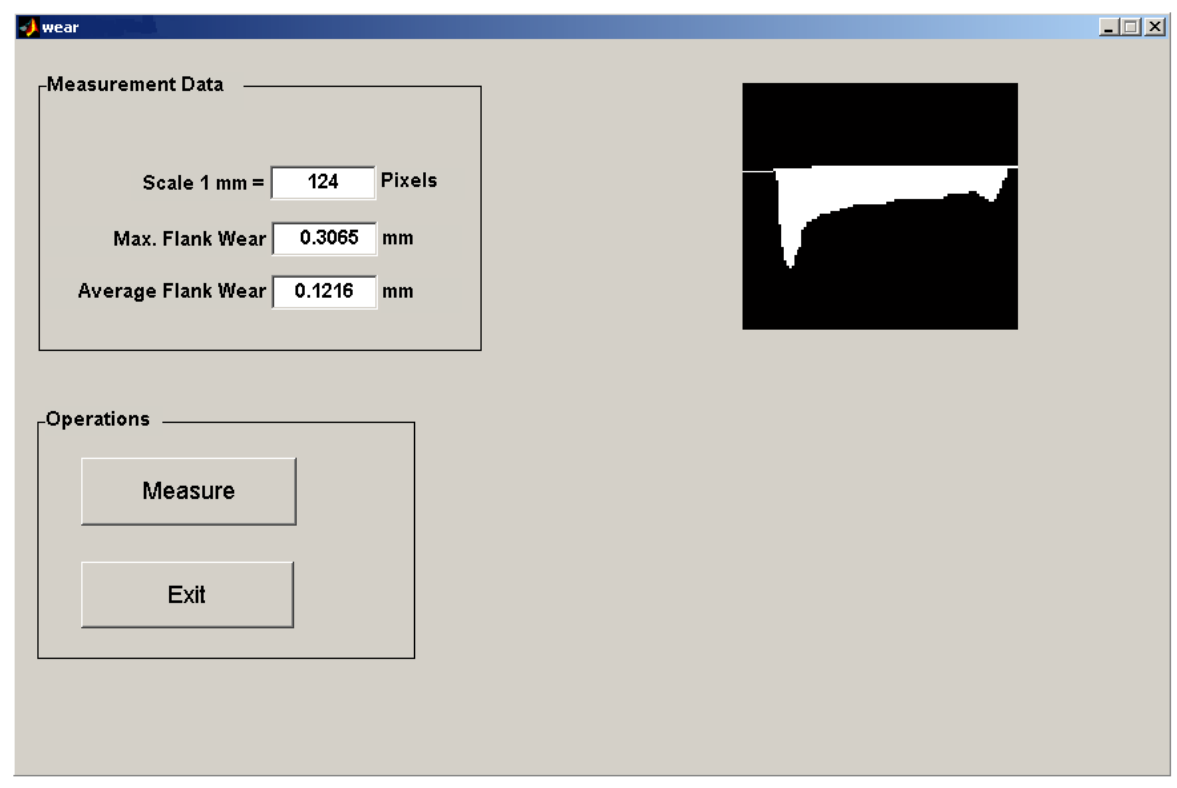

Fig.4. Wear measurement dialog box and the wear data.

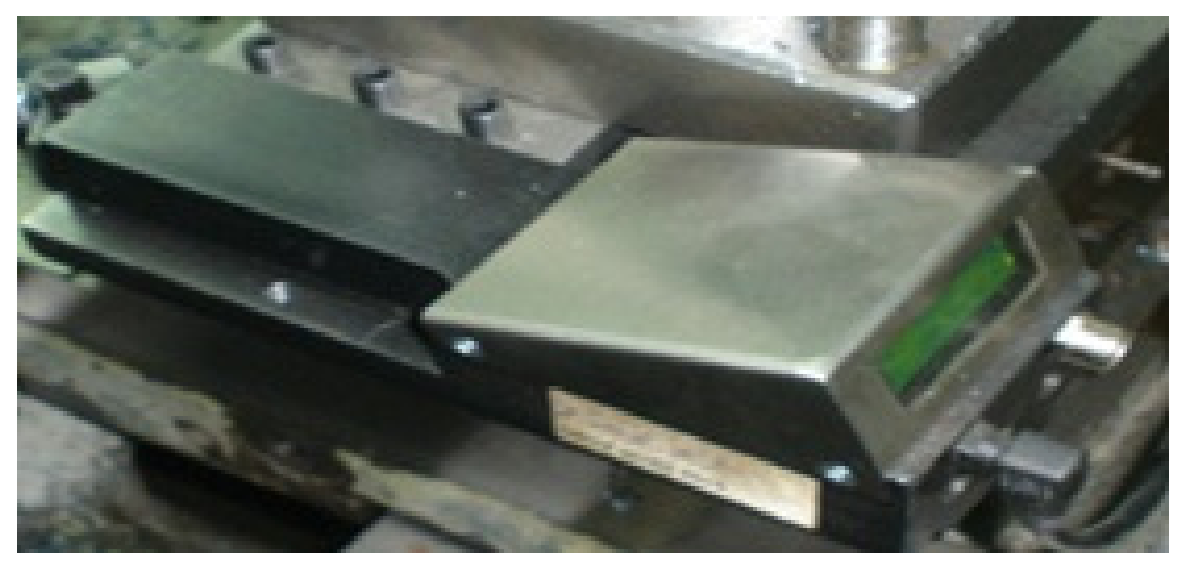

Fig.5. Force dynamometer, the tool holder and the LCD display.

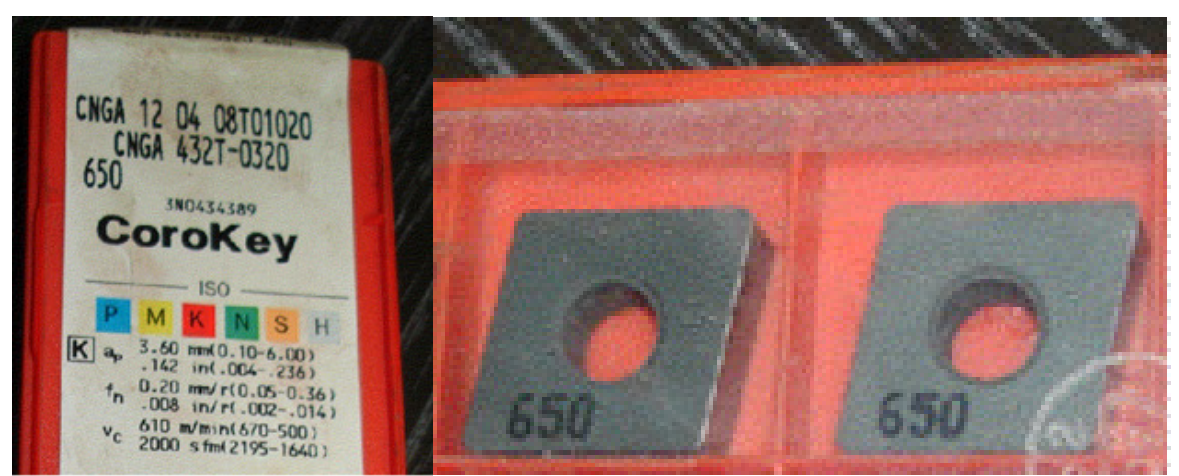

Fig.6. Tool inserts. 


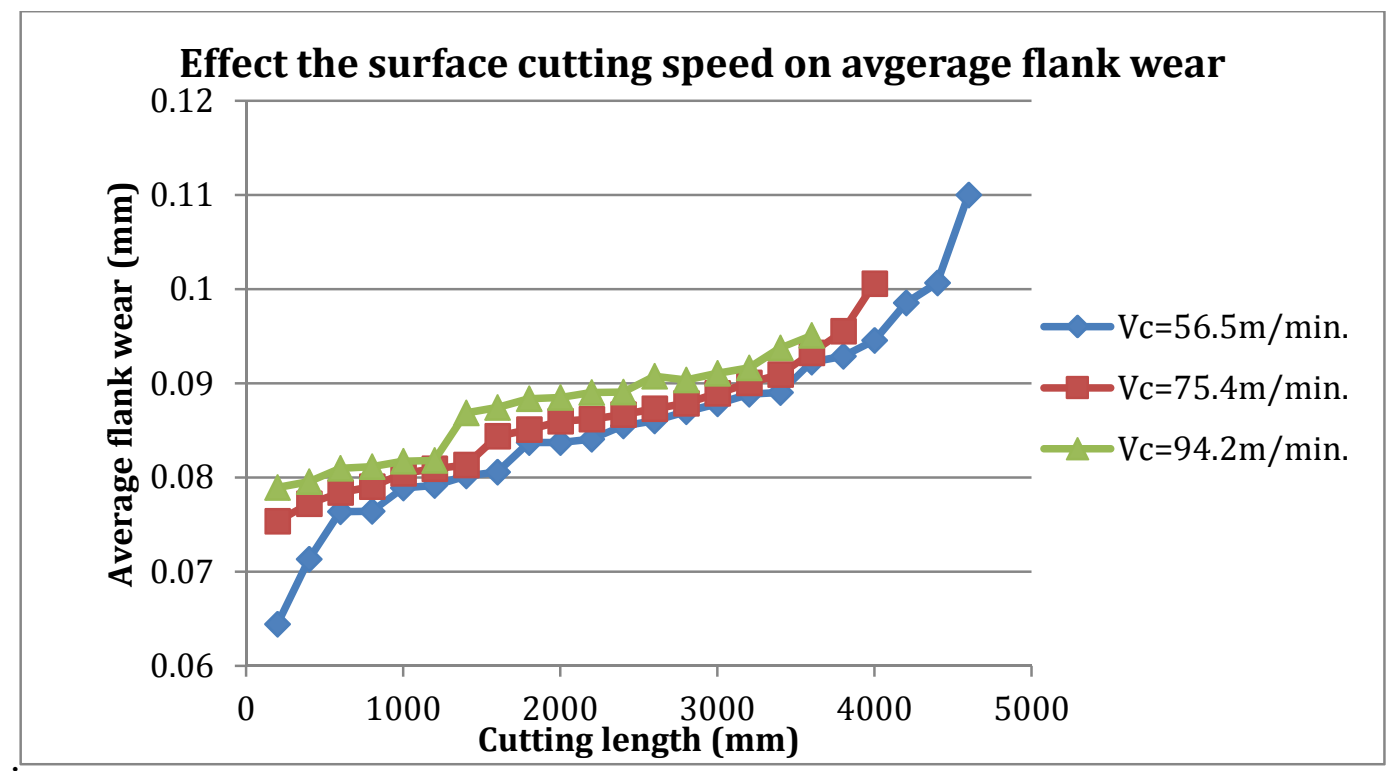

Fig.7. Effect of surface cutting speed on average flank tool wear.

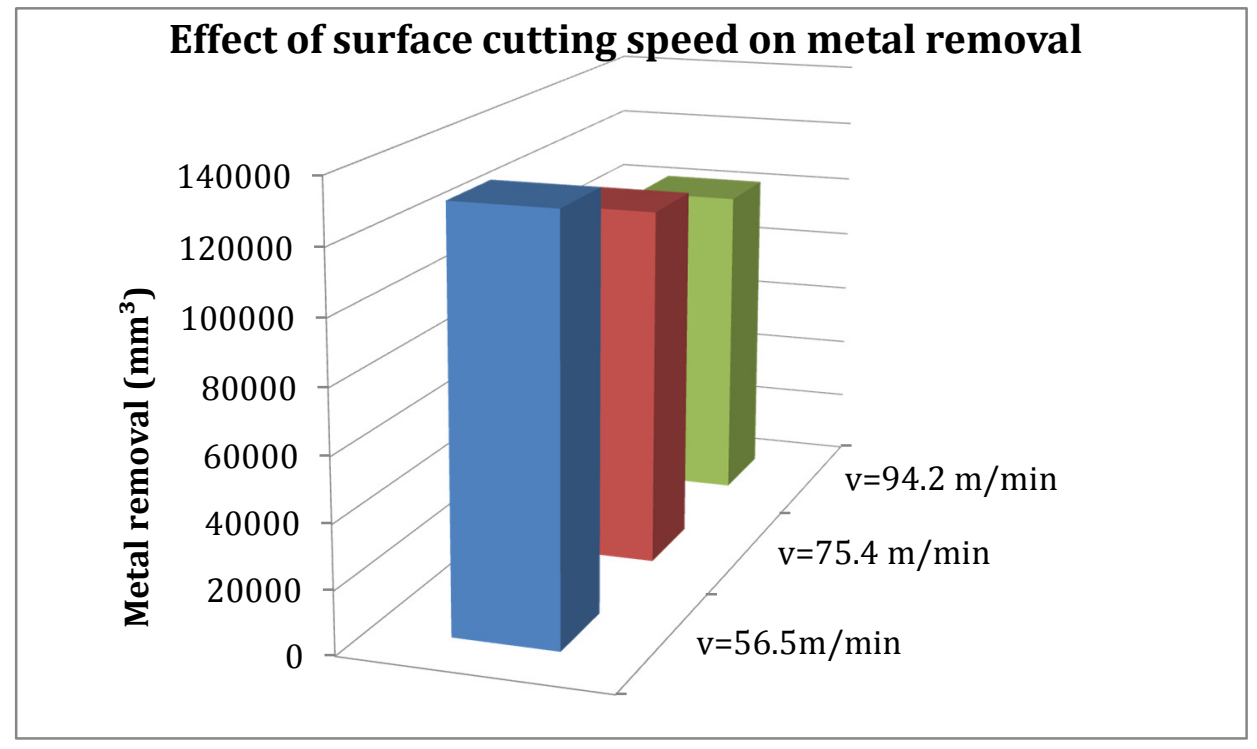

Fig.8. Effect of surface cutting speed on metal removal.
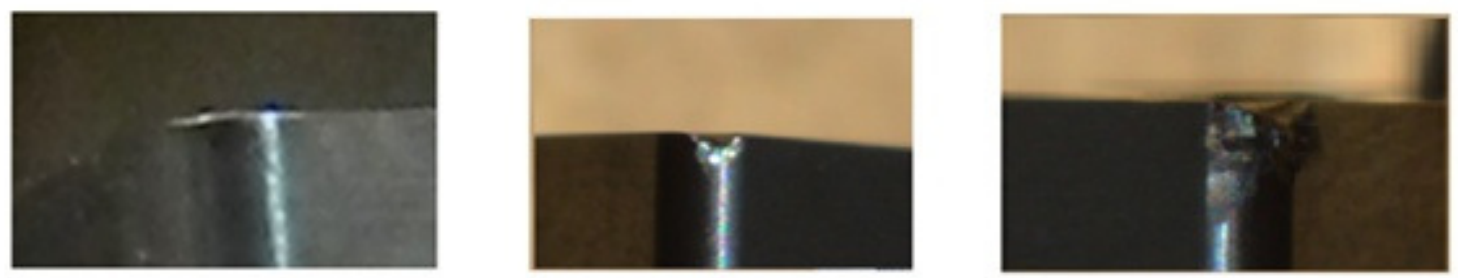

Fig.9. Tool flank wear and failure after the end of the experiment. 


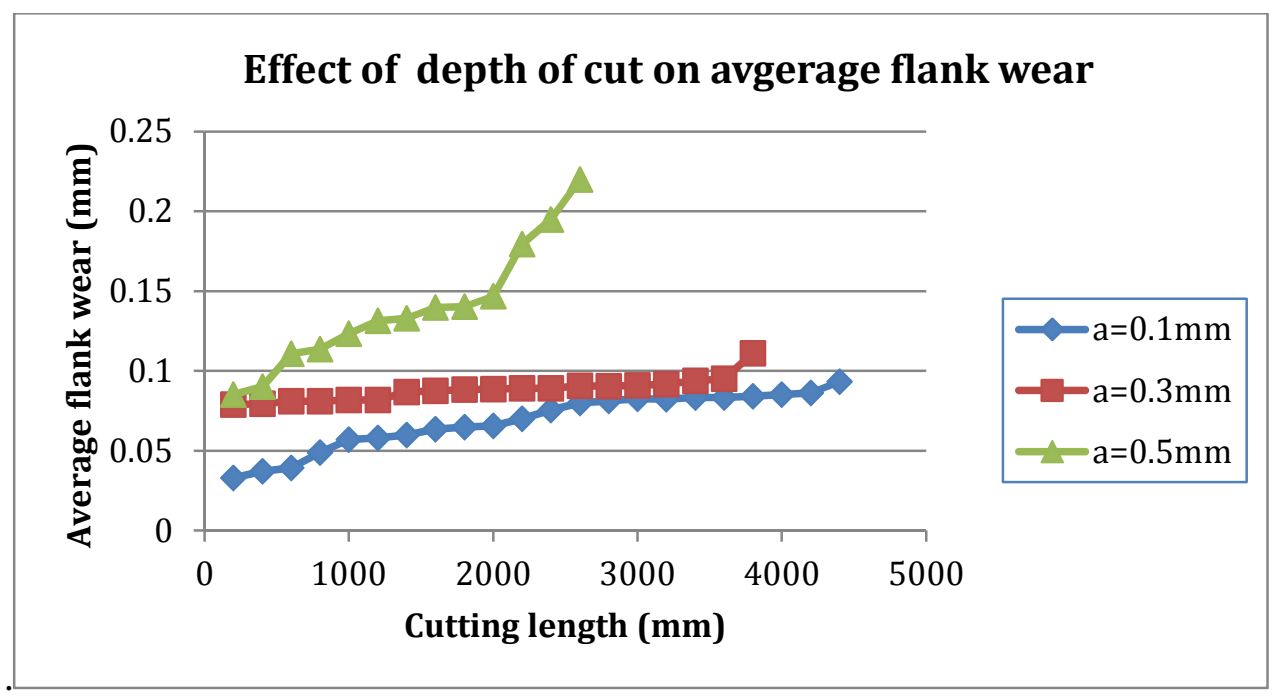

Fig.10. Effect of depth of cut on average flank tool wear.

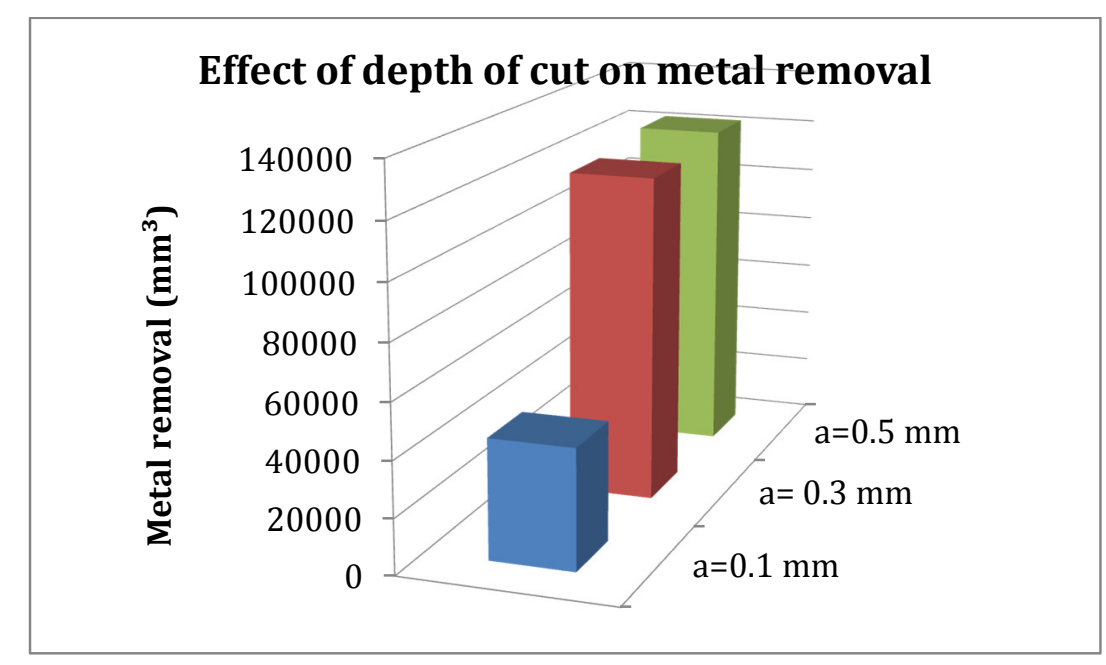

Fig.11. Effect of depth of cut on metal removal.

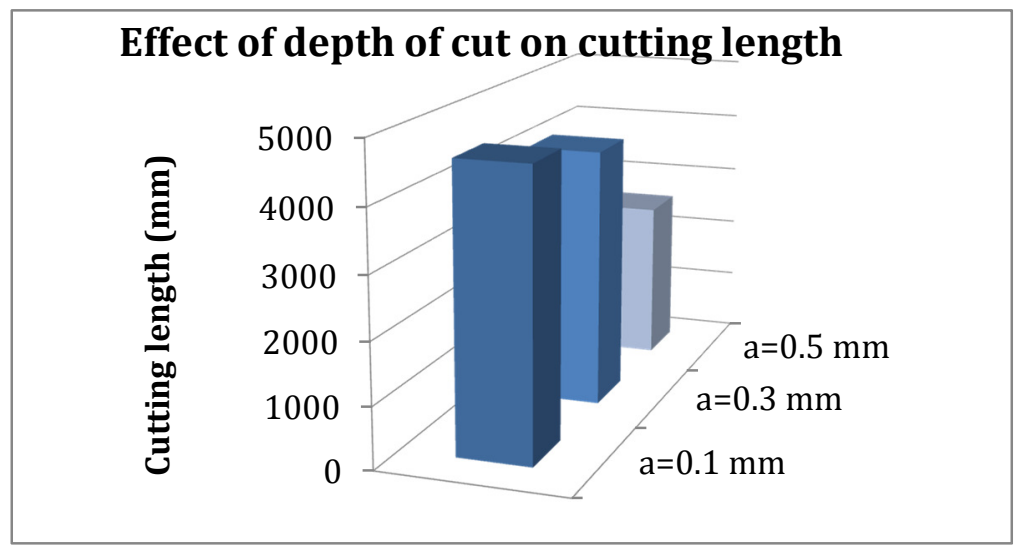

Fig.12. Effect of depth of cut on cutting length. 


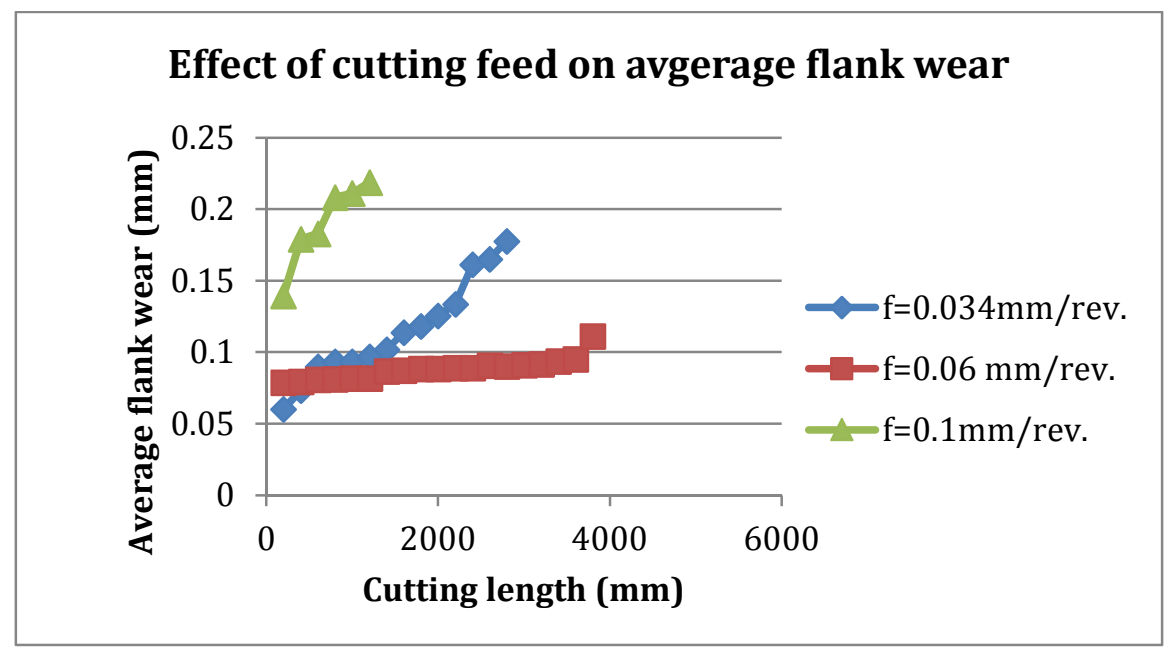

Fig.13. Effect of cutting feed rate on average flank tool wear.

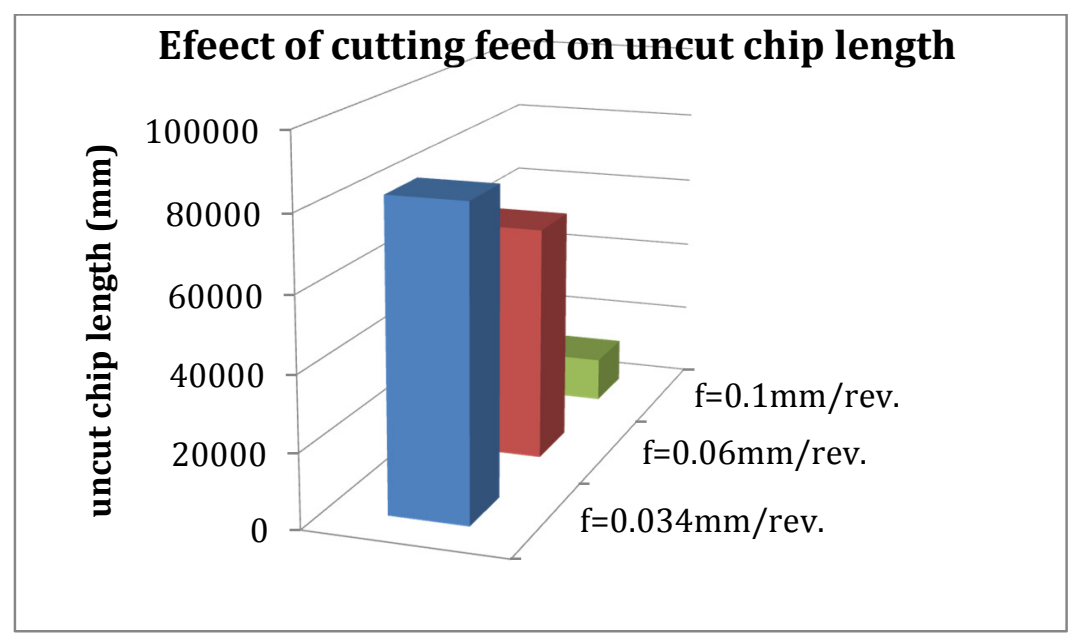

Fig.14. Effect of cutting feed on uncut chip length.

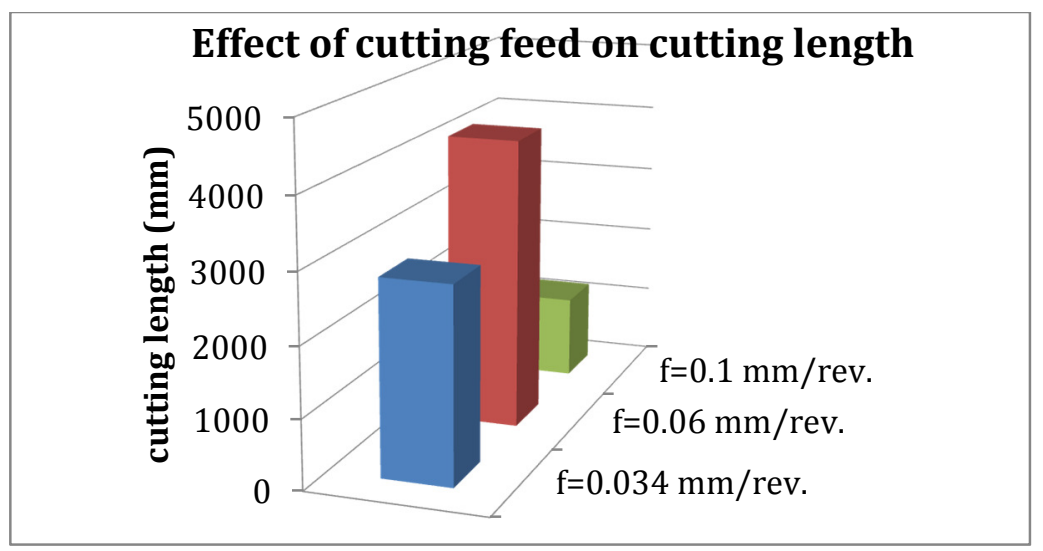

Fig.15. Effect of cutting feed on cutting length. 


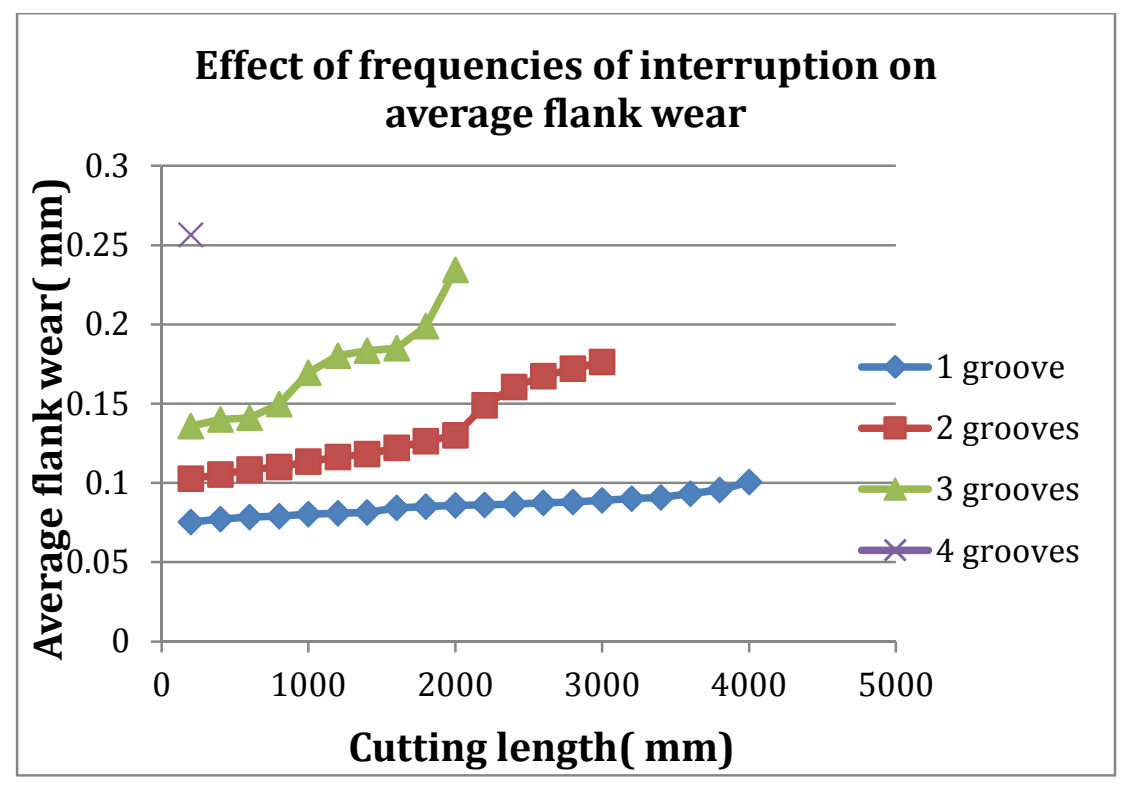

Fig.16. Effect of frequencies of interruption on average flank wear.

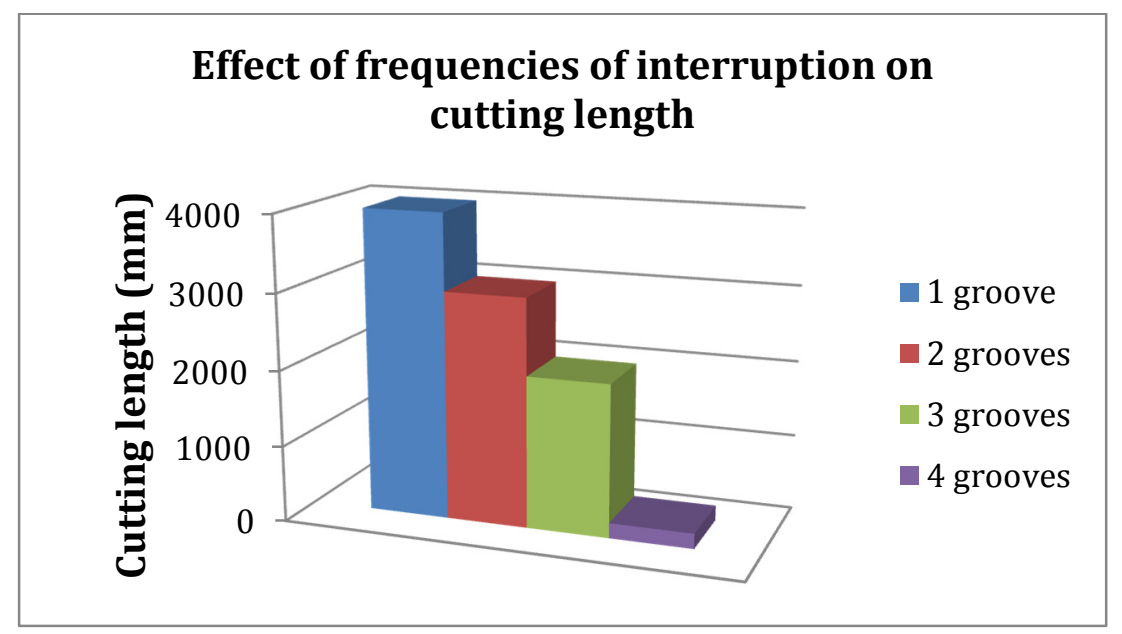

Fig.17. Effect of frequencies of interruption on cutting length.

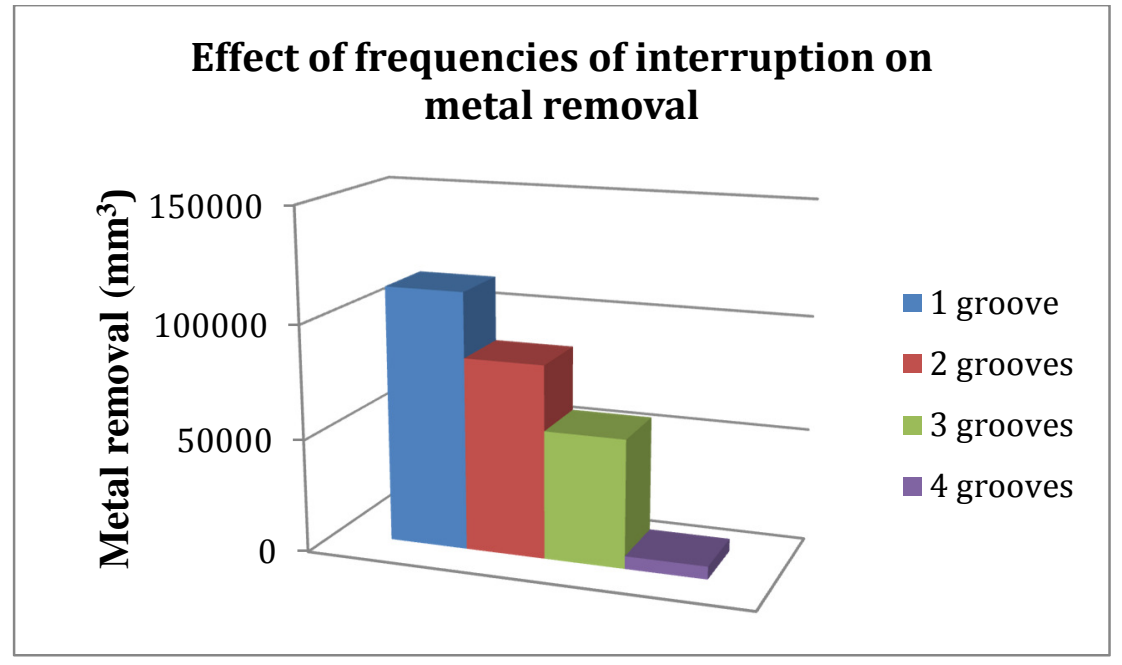

Fig.18. Effect of frequencies of interruption on metal removal. 
Table 1. Shows the chemical properties of the work materials.

\begin{tabular}{|c|c|c|c|c|c|c|c|c|c|}
\hline Constituent & C & Si & $\mathbf{P}$ & $\mathrm{S}$ & $\mathrm{Cr}$ & Mo & Mn & HB & $\begin{array}{l}\text { ou } \\
\mathbf{N} / \mathbf{m m}^{2}\end{array}$ \\
\hline $\begin{array}{l}\text { Chemical Composition } \\
\text { (\% by mass) }\end{array}$ & $\begin{array}{l}0.38 \\
0.45\end{array}$ & 0.4 & 0.035 & 0.035 & $\begin{array}{l}0.9 \\
1.2\end{array}$ & $\begin{array}{l}0.15 \\
0.3\end{array}$ & $\begin{array}{l}0.6 \\
0.9\end{array}$ & 241 & $\begin{array}{l}1000 \\
1200\end{array}$ \\
\hline
\end{tabular}

